\title{
The Effects of Bolus Volume and Texture on Pharyngeal Pressure Events Using High-resolution Manometry and Its Comparison with Videofluoroscopic Swallowing Study
}

\author{
Ju Seok Ryu, ${ }^{1 *}$ Donghwi Park, ${ }^{1}$ Yoongul Oh, ${ }^{2}$ Seok Tae Lee, ${ }^{2}$ and Jin Young Kang ${ }^{3}$ \\ ${ }^{I}$ Department of Rehabilitation Medicine, Seoul National University Bundang Hospital, Seoul National University College of Medicine, \\ Seongnam, Korea; ${ }^{2}$ Department of Rehabilitation Medicine, CHA Bundang Medical Center, CHA University, Seongnam, Korea; and ${ }^{3}$ Department \\ of Rehabilitation Medicine, St. Paul's Hospital, College of Medicine, The Catholic University, Seoul, Korea
}

\section{Background/Aims}

The purpose of this study was to develop new parameters of high-resolution manometry (HRM) and to applicate these to quantify the effect of bolus volume and texture on pharyngeal swallowing.

\section{Methods}

Ten healthy subjects prospectively swallowed dry, thin fluid $2 \mathrm{~mL}$, thin fluid $5 \mathrm{~mL}$, thin fluid $10 \mathrm{~mL}$, and drinking twice to compare effects of bolus volume. To compare effect of texture, subjects swallowed thin fluid $5 \mathrm{~mL}$, yogurt $5 \mathrm{~mL}$, and bread twice. A 32 -sensor HRM catheter and BioVIEW ANALYSIS software were used for data collection and analysis. HRM data were synchronized with kinematic analysis of videofluoroscopic swallowing study (VFSS) using epiglottis tilting.

\section{Results}

Linear correlation analysis for volume showed significant correlation for area of velopharynx, duration of velopharynx, pre-upper esophageal sphincter (UES) maximal pressure, minimal UES pressure, UES activity time, and nadir UES duration. In the correlation with texture, all parameters were not significantly different. The contraction of the velopharynx was faster than laryngeal elevation. The durations of UES relaxation was shorter in the kinematic analysis than HRM.

\section{Conclusions}

The bolus volume was shown to have significant effect on pharyngeal pressure and timing, but the texture did not show any effect on pharyngeal swallowing. The parameters of HRM were more sensitive than those of kinematic analysis. As the parameters of HRM are based on precise anatomic structure and the kinematic analysis reflects the actions of multiple anatomic structures, HRM and VFSS should be used according to their purposes.

(J Neurogastroenterol Motil 2016;22:231-239)

Key Words

Biomechanics; Deglutition; Deglutition disorders; Manometry; Pressure

Received: June 2, 2015 Revised: October 14, 2015 Accepted: November 12, 2015

() This is an Open Access article distributed under the terms of the Creative Commons Attribution Non-Commercial License (http:// creativecommons. org/licenses/by-nc/4.0) which permits unrestricted non-commercial use, distribution, and reproduction in any medium, provided the original work is properly cited.

*Correspondence: Ju Seok Ryu, MD, PhD

Department of Rehabilitation Medicine, Seoul National University Bundang Hospital, Seoul National University College of Medicine, 82 Gumi-ro 173 Beon-gil, Bundang-gu, Seongnam 13620, Korea Tel: +82-31-787-7739, Fax: +82-31-787-4051, E-mail: jseok337@snu.ac.kr 


\section{Introduction}

The analysis of pharyngeal pressure is important to reveal the underlying pathophysiology of deglutition. Several studies using conventional manometry were performed to evaluate the effect of volume on pharyngeal dysphagia. ${ }^{1-3}$ In a previous study, the major effects of increased volume were earlier onset of anterior tongue base (TB) movement, superior palatal movement, anterior laryngeal movement, and upper esophageal sphincter (UES) opening. ${ }^{3}$ In other studies that evaluated the TB, no change in pressure was found, ${ }^{1,4}$ while an increase in duration of activity was observed. ${ }^{1,5}$ While these studies have informed the physiology, pathophysiology of swallowing, and technical limitations in accurate analysis of pressure events. As the pharynx is composed of a diverse small anatomical structure, conventional manometry has significant limitations when used for the evaluation of pharyngeal dysphagia, such as limited sensors, large space between sensors, and the use of the hydrostatic pressure.

Accurate analysis of the rapidly changing pressures along the pharynx requires greater spatial and temporal resolution than are allowed by conventional manometry. The high-resolution manometry (HRM) has overcome these pitfalls. Pressure sensors are located at $1-\mathrm{cm}$ interval and uses a solid catheter which allow the evaluation in the sitting position. It also has improved sensitivity, reliability, and accuracy. ${ }^{6}$ Though informative with potentially high clinical value, it has yet to be applied routinely to the assessment of dysphagia.

HRM has revealed subtle pressure differences not previously detected by conventional manometry successfully. ${ }^{6-10}$ As HRM measures the pressure generation in pharyngeal structures, the main target structures are the velopharynx (VP), TB, epiglottis, and the UES. ${ }^{7,11} \mathrm{VP}$ is the region between the soft palate and pharyngeal wall. ${ }^{7} \mathrm{VP}$ acts as a sphincter between the nasopharynx and pharynx. TB is located between the VP and UES. The piston like action against the pharyngeal constrictors drives the bolus through the pharynx and into the UES. ${ }^{12}$ The UES region was defined as the midpoint of stable high pressure just distal (rostral) to the baseline low esophageal pressure zone, extending to a point of low esophageal pressure distally and low baseline pharyngeal pressure proximally. ${ }^{7}$

In previous studies that evaluated the effect of bolus volume on UES, the UES opening duration and the minimum pressures changed significantly with increased bolus volume. ${ }^{13}$ When accommodating a larger bolus, the UES opens wider and remains open longer. ${ }^{13,14}$ Till now, few studies were performed to evaluate the ef- fect of bolus volume and texture on the entire pharyngeal swallow with HRM. ${ }^{15,16}$ HRM is capable of providing information on how the bolus volume and texture precisely affects swallowing physiology. If we employ new parameters based on anatomic structures that are important for the mechanisms of dysphagia, HRM could present more comprehensive and precise information for understanding dysphagia. Also, the comparison between HRM and videofluoroscopic swallowing study (VFSS) could expand the understanding of pharyngeal swallowing.

In the present study, we quantified the effect of bolus volume and texture on pharyngeal pressure events using HRM, and compared HRM with kinematic analysis of VFSS.

\section{Materials and Methods}

\section{Subjects}

Ten subjects participated in this study with the approval of the Institutional Review Board. All subjects were without swallowing, neurological, or gastrointestinal disorders. Participants were instructed not to eat for 4 hours and not to drink liquids for 2 hours prior to testing to avoid any potential confounding effect of satiety. The average age of the 10 subjects is $29.2 \pm 7.2$. Seven were male and 3 were female.

\section{Methods}

\section{Analysis of high-resolution manometry data}

A solid HRM that can measure subtle pressures along the pharynx was used for all data collection (INSIGHT HRM; Sandhill Scientific Instruments, Highlands Ranch, CO, USA). ${ }^{14}$ The manometric catheter uses 32 circumferential pressure sensors spaced $1 \mathrm{~cm}$ apart.

Ten percent lidocaine spray was applied through the nasal passage. The manometric catheter was lubricated with $2 \%$ lidocaine jelly to ease passage of the catheter through the pharynx. Once the catheter was positioned within the pharynx, participants rested for 5-10 minutes for adaptation prior to performing the experimental swallows.

In the neutral head position, the participants received dry, 2, $5,10 \mathrm{~mL}$, and self-adjusted drinking twice for the analysis of thin fluid volume. For the texture evaluation, the participants received 5 $\mathrm{mL}$ liquid, $5 \mathrm{~mL}$ yogurt, and bread twice. Liquid and yogurt were delivered to the oral cavity via a syringe. Therefore a total of 16 swallows were analyzed for each participant. 
Pressure and timing data were extracted manually using a BioVIEW ANALYSIS software (Sandhill Scientific, Version 5.6.3.0). The areas of interest were VP, TB, low pharynx (LP), and UES (Fig. 1A). ${ }^{6,7,11}$

Anatomically $\mathrm{TB}$ pressure is generated at a similar level with the epiglottic pressure. As tilting of the epiglottis strikes the manometric catheter, the tilting epiglottis changes the peak pressure and the area integral ([1] peak in Fig. 1A). Therefore, we measured the higher pressure peak at one level higher or lower to the epiglottis level for the TB pressure. LP peak was measured between the TB and UES. This peak was shallow and had peristaltic components. The UES peak was the broad peak below the shallow LP peak. Therefore, the LP peak represents the inferior pharyngeal constrictor and the UES peak represents the cricopharyngeus muscles (Fig. 1A). ${ }^{11}$

Mean and standard deviation values were recorded for maximum pressure, area integral, rise time and duration in the regions of the VP and TB. We measured the maximal peak pressure in the

\section{A}

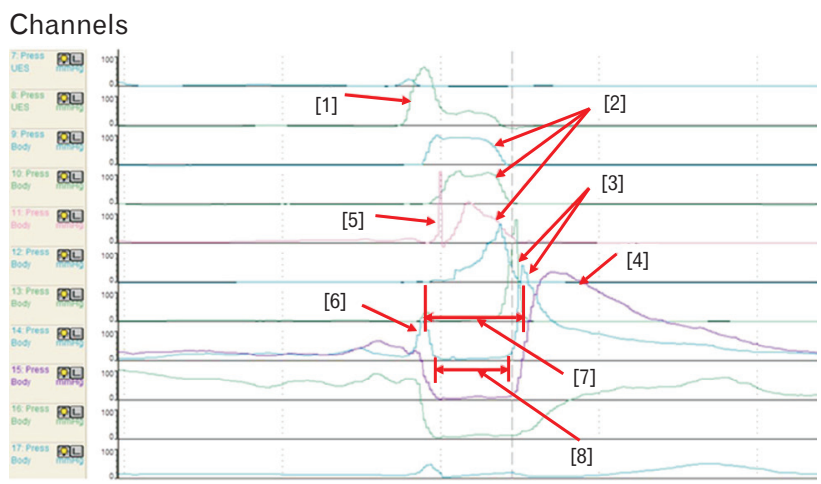

B

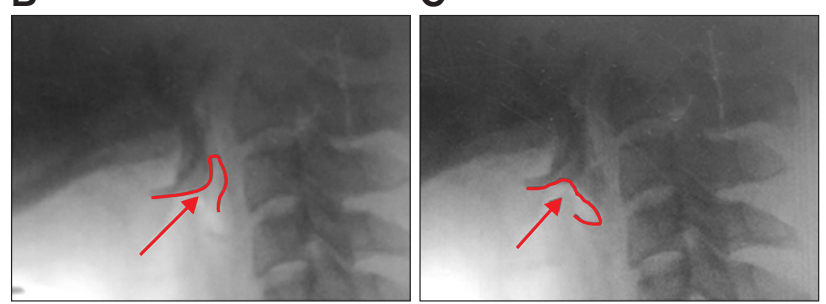

Figure 1. These figures show the parameters of high resolution manometer. (A) The individual peaks in the areas of interest. Each peak shows [1] velopharyngeal peak, [2] tongue base (TB) peaks, [3] low pharyngeal peak, [4] upper esophageal sphincter (UES) peak, [5] tilting of epiglottis, [6] pre-UES peak, [7] UES activity time, and [8] Nadir UES duration. The [5] peak shows the epiglottic tilting peak in front of the TB peak. (B) The contact of bolus with epiglottis. (C) The tilting of epiglottis. At this time, the tilted epiglottis strikes the manometric catheter, resulting in the peak [5]. region of the LP. We also measured the pre-UES maximal pressure, post-UES maximal pressure, minimal UES pressure, UES activity time (the interval between pre-UES peak and post-UES peak), and the nadir UES duration in the region of UES. The time intervals between VP onset and epiglottis peak, VP onset and TB onset, VP peak and epiglottis peak, VP peak and TB peak, VP onset and pre-UES peak, and VP onset and post-UES peaks were also measured. Using the results obtained, we calculated the rate of pressure generation (ROP) in VP, TB (maximal peak amplitude/ rise time), and pressure wave velocity (the distance from the VP pressure peak to the maximal post-swallow UES pressure peak/the time difference between these 2 points). ${ }^{11,17}$

\section{Kinematic analysis of laryngeal structure and synchronization with high-resolution manometry}

We measured various time intervals during VFSS, as recorded by a camcorder (SMX-C14, Samsung Electronics, Suwon, Gyeonggi-do, South Korea) running at 30 frames per second, including that of the epiglottis contact with the bolus, laryngeal elevation, pharyngeal constriction, and UES opening, by using a multimedia player (Gomplayer; Gretech, Seoul, South Korea). ${ }^{18-20}$

We synchronized the kinematic and HRM data based on epiglottis tilting (Fig. 1B and 1C). We used the peak of epiglottis tilting in HRM ([1] peak in Fig. 1A) for synchronization of kinematic analysis (Fig. 1B and 1C). For the synchronization process, we analyzed the chronological sequence of normal swallowing and compared parameters between the VFSS and HRM.

\section{Statistical Methods}

SPSS 21.0 software (SPSS Inc, Chicago, IL, USA) was used for statistical analyses. Spearman's rank correlation test was used to analyze how each dependent variable (pharyngeal pressure or timing event) changed across bolus volume. The results of variables for different volume and texture were analyzed using the KruskalWallis test. For post-hoc analysis, the Bonferroni method was used. Values were presented as average \pm standard deviation. A significance level of $\alpha=0.05$ was determined a-priori.

\section{Results}

\section{Correlation with Volume}

On VP, the linear correlation analysis showed significant correlation for area integral of $\mathrm{VP}(r=0.238, P=0.016)$ and duration of $\mathrm{VP}(r=0.224, P=0.024)$, but not with maximal pressure and 
rise time of VP (Table 1). All parameters of TB had no significant correlation $(P>0.05$; Table 1). On UES, pre-UES maximal pressure $(r=-0.248, P=0.012)$, minimal UES pressure $(r=0.294$, $P=0.003)$, UES activity time $(r=0.215, P=0.031)$, and nadir UES duration $(r=0.427, P<0.001)$ showed significant correlation with increasing volume (Table 1).

The interval from VP onset and TB onset $(r=0.176, P=$ 0.079), VP peak and TB peak ( $r=-0.177, P=0.076)$, and VP onset and pre-UES peak $(r=-0.188, P=0.059)$ were not statis- tically significant, but showed a tendency (Table 2).

\section{The Comparison Between Groups According to Volume}

On comparison among the 5 groups of different bolus volume, post-UES maximal pressure, minimal UES pressure, nadir UES duration, and the time interval between the VP onset and TB onset were significantly different $(P<0.05)$. On post-hoc analysis, minimal UES pressure was significantly different between dry and drinking $(P=0.033)$, nadir UES duration was significantly dif-

Table 1. The Visuospatial Variables of High-resolution Manometry According to Bolus Volume

\begin{tabular}{|c|c|c|c|c|c|c|c|c|}
\hline & & \multirow{2}{*}{ Dry } & \multirow{2}{*}{$2 \mathrm{~mL}$} & \multirow{2}{*}{$5 \mathrm{~mL}$} & \multirow{2}{*}{$10 \mathrm{~mL}$} & \multirow{2}{*}{ Drinking } & \multicolumn{2}{|c|}{ Correlation } \\
\hline & & & & & & & $r$ & $P$-value \\
\hline \multirow[t]{4}{*}{$\mathrm{VP}$} & Max pressure (mmHg) & $192.40 \pm 83.95$ & $217.84 \pm 100.80$ & $232.45 \pm 107.66$ & $242.92 \pm 116.74$ & $224.12 \pm 94.73$ & 0.142 & 0.156 \\
\hline & Area $(\mathrm{mmHg} \cdot \mathrm{sec})^{\mathrm{a}}$ & $41.00 \pm 25.55$ & $46.25 \pm 26.91$ & $49.60 \pm 32.80$ & $61.10 \pm 46.99$ & $63.95 \pm 42.99$ & 0.238 & 0.016 \\
\hline & Rise time (sec) & $0.20 \pm 0.16$ & $0.18 \pm 0.12$ & $0.15 \pm 0.76$ & $0.15 \pm 0.08$ & $0.23 \pm 0.13$ & 0.086 & 0.394 \\
\hline & Duration $(\mathrm{sec})^{\mathrm{a}}$ & $0.33 \pm 0.17$ & $0.31 \pm 0.15$ & $0.37 \pm 0.17$ & $0.38 \pm 0.20$ & $0.47 \pm 0.22$ & 0.224 & 0.024 \\
\hline \multirow[t]{4}{*}{ TB } & Max pressure(mmHg) & $144.94 \pm 47.24$ & $141.03 \pm 30.43$ & $142.14 \pm 30.31$ & $142.41 \pm 33.37$ & $189.66 \pm 134.87$ & 0.109 & 0.278 \\
\hline & Area $(\mathrm{mmHg} \cdot \mathrm{sec})$ & $51.90 \pm 15.25$ & $56.45 \pm 21.13$ & $53.00 \pm 16.82$ & $53.35 \pm 16.20$ & $47.10 \pm 16.75$ & -0.099 & 0.325 \\
\hline & Rise time (sec) & $0.27 \pm 0.10$ & $0.27 \pm 0.10$ & $0.26 \pm 0.09$ & $0.31 \pm 0.11$ & $0.26 \pm 0.11$ & 0.059 & 0.557 \\
\hline & Duration (sec) & $0.55 \pm 0.14$ & $0.59 \pm 0.16$ & $0.57 \pm 0.16$ & $0.62 \pm 0.18$ & $0.56 \pm 0.17$ & 0.032 & 0.749 \\
\hline $\begin{array}{l}\text { Low } \\
\text { pharynx }\end{array}$ & Max pressure $(\mathrm{mmHg})$ & $450.8 \pm 133.31$ & $495.22 \pm 163.29$ & $486.58 \pm 150.17$ & $462.68 \pm 147.19$ & $447.31 \pm 148.53$ & -0.030 & 0.762 \\
\hline \multirow[t]{5}{*}{ UES } & $\begin{array}{l}\text { Pre-UES max pressure } \\
(\mathrm{mmHg})^{\mathrm{a}}\end{array}$ & $268.25 \pm 84.00$ & $251.96 \pm 87.54$ & $240.58 \pm 119.60$ & $220.53 \pm 98.18$ & $205.86 \pm 63.66$ & -0.248 & 0.012 \\
\hline & $\begin{array}{l}\text { Post-UES max pressure } \\
(\mathrm{mmHg})\end{array}$ & $377.28 \pm 129.41$ & $457.21 \pm 121.27$ & $452.13 \pm 126.20$ & $443.10 \pm 110.37$ & $357.21 \pm 145.88$ & -0.054 & 0.294 \\
\hline & Min pressure $(\mathrm{mmHg})^{\mathrm{a}}$ & $-11.65 \pm 9.10$ & $-8.03 \pm 4.40$ & $-6.21 \pm 5.43$ & $-4.98 \pm 6.30$ & $-2.95 \pm 16.01$ & 0.294 & 0.003 \\
\hline & Activity time $(\mathrm{sec})^{\mathrm{a}}$ & $0.67 \pm 0.16$ & $0.69 \pm 0.14$ & $0.69 \pm 0.13$ & $0.70 \pm 0.10$ & $0.75 \pm 0.190$ & 0.215 & 0.031 \\
\hline & Nadir duration $(\mathrm{sec})^{\mathrm{a}}$ & $0.27 \pm 0.09$ & $0.33 \pm 0.09$ & $0.38 \pm 0.10$ & $0.37 \pm 0.11$ & $0.40 \pm 0.10$ & 0.427 & $<0.001$ \\
\hline
\end{tabular}

${ }^{\mathrm{a}} \mathrm{P}<0.05$.

VP, velopharynx; TB, tongue base; UES, upper esophageal sphincter; Max, maximal; Min, minimal.

Table 2. The Time Variables of High-resolution Manometry According to Bolus Volume

\begin{tabular}{|c|c|c|c|c|c|c|c|c|}
\hline & & \multirow{2}{*}{ Dry } & \multirow{2}{*}{$2 \mathrm{~mL}$} & \multirow{2}{*}{$5 \mathrm{~mL}$} & \multirow{2}{*}{$10 \mathrm{~mL}$} & \multirow{2}{*}{ Drinking } & \multicolumn{2}{|c|}{ Correlation } \\
\hline & & & & & & & $r$ & $P$-value \\
\hline \multirow{6}{*}{$\begin{array}{l}\text { Time } \\
\text { intervals }\end{array}$} & VP onset - epiglottis (sec) & $0.41 \pm 0.23$ & $0.37 \pm 0.19$ & $0.36 \pm 0.19$ & $0.36 \pm 0.17$ & $0.38 \pm 0.18$ & -0.032 & 0.759 \\
\hline & $\mathrm{VP}$ onset - TB onset (sec) & $0.20 \pm 0.14$ & $0.17 \pm 0.13$ & $0.14 \pm 0.07$ & $0.19 \pm 0.12$ & $0.29 \pm 0.19$ & 0.176 & 0.079 \\
\hline & VP peak - epiglottis (sec) & $0.24 \pm 0.17$ & $0.21 \pm 0.16$ & $0.21 \pm 0.15$ & $0.21 \pm 0.13$ & $0.17 \pm 0.09$ & -0.079 & 0.441 \\
\hline & VP peak - TB peak (sec) & $0.31 \pm 0.09$ & $0.32 \pm 0.11$ & $0.31 \pm 0.10$ & $0.33 \pm 0.07$ & $0.26 \pm 0.09$ & -0.177 & 0.076 \\
\hline & VP onset - pre-UES (sec) & $0.24 \pm 0.14$ & $0.20 \pm 0.12$ & $0.26 \pm 0.27$ & $0.17 \pm 0.10$ & $0.19 \pm 0.17$ & -0.188 & 0.059 \\
\hline & VP onset - post-UES (Sec) & $0.97 \pm 0.17$ & $0.95 \pm 0.18$ & $0.92 \pm 0.11$ & $0.96 \pm 0.11$ & $0.97 \pm 0.24$ & 0.014 & 0.888 \\
\hline \multirow[t]{3}{*}{$\mathrm{ROP}$} & ROP, VP (mmHg/sec) & $1393.7 \pm 831.2$ & $1640.8 \pm 1051.4$ & $1810.9 \pm 1173.1$ & $1816.6 \pm 1135.9$ & $1355.0 \pm 976.0$ & -0.008 & 0.940 \\
\hline & ROP, TB (mmHg/sec) & $595.6 \pm 262.9$ & $597.2 \pm 244.8$ & $656.4 \pm 328.2$ & $534.4 \pm 240.7$ & $881.1 \pm 582.4$ & 0.064 & 0.524 \\
\hline & $\begin{array}{l}\text { ROP, VP onset - post-UES } \\
(\mathrm{cm} / \mathrm{sec})\end{array}$ & $7.12 \pm 1.71$ & $7.43 \pm 1.28$ & $7.68 \pm 1.38$ & $7.36 \pm 1.08$ & $7.07 \pm 1.29$ & -0.020 & 0.845 \\
\hline
\end{tabular}

VP, velopharynx; TB, tongue base; UES, upper esophageal sphincter; ROP, rate of pressure generation. 
ferent between dry swallow and bolus volumes of $5 \mathrm{cc}$ and above $(P$ $<0.05)$. The interval between $\mathrm{VP}$ onset and $\mathrm{TB}$ was significantly different between $5 \mathrm{cc}$ and drinking $(P=0.016)$. The ROP of TB was significantly different between $10 \mathrm{cc}$ and drinking $(P=0.026)$, but the post-hoc analysis for post-UES maximal pressure was not significantly different $(P>0.05)$ (Fig. 2A).

\section{Correlation with Texture}

All parameters were not significantly different according to texture (Tables 3 and 4).

\section{The Comparison Between Groups According to Texture}

In the comparison among the 3 groups of texture, all parameters were not significantly different. Only the interval between VP peak and epiglottis showed a tendency $(P=0.088)($ Fig. 2B).

The Comparison Between High-resolution Manometry and Kinematic Analysis of Videofluoroscopic Swallowing Study

The contraction of the VP was the fastest event, followed by the
A
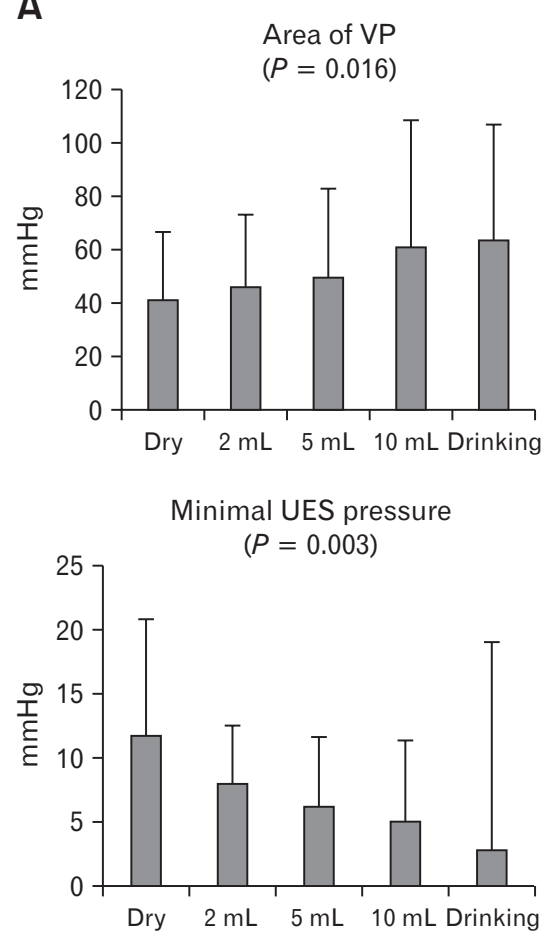
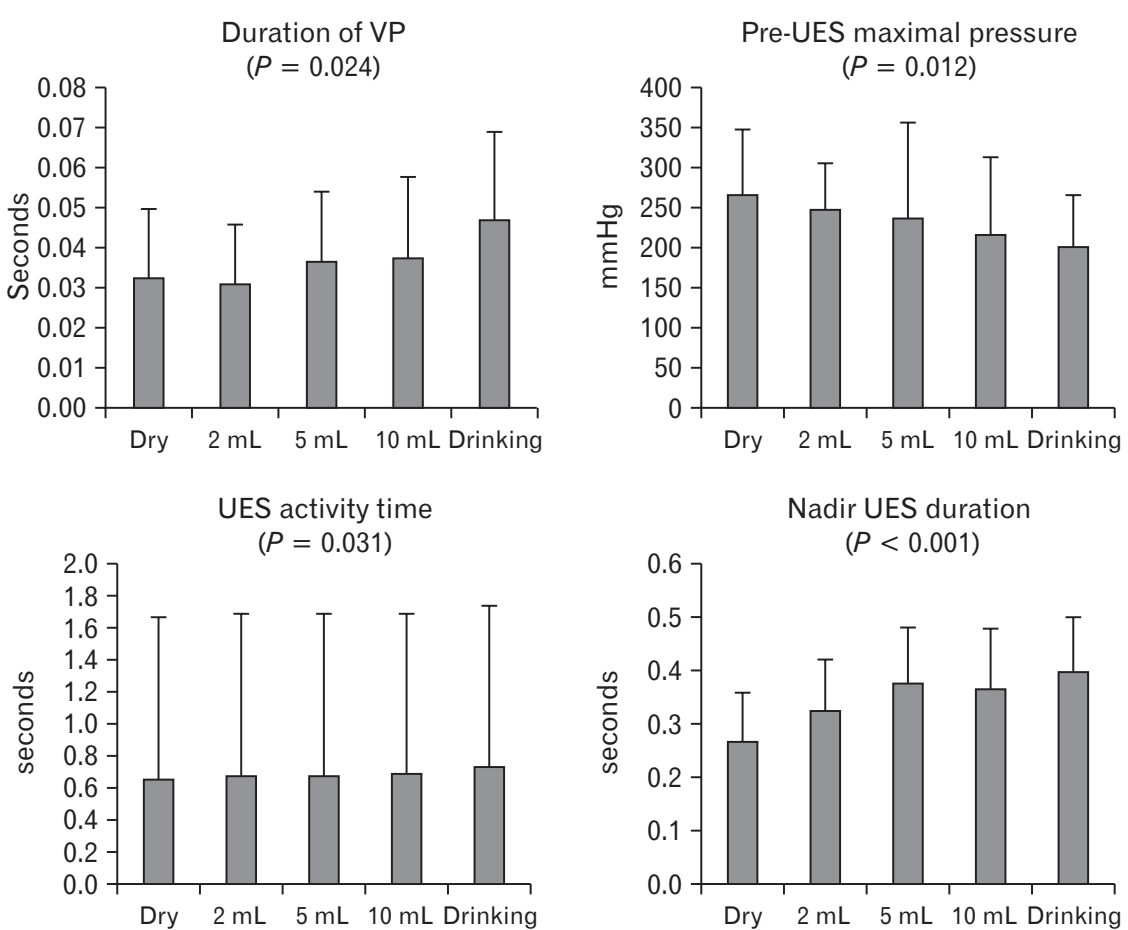

B
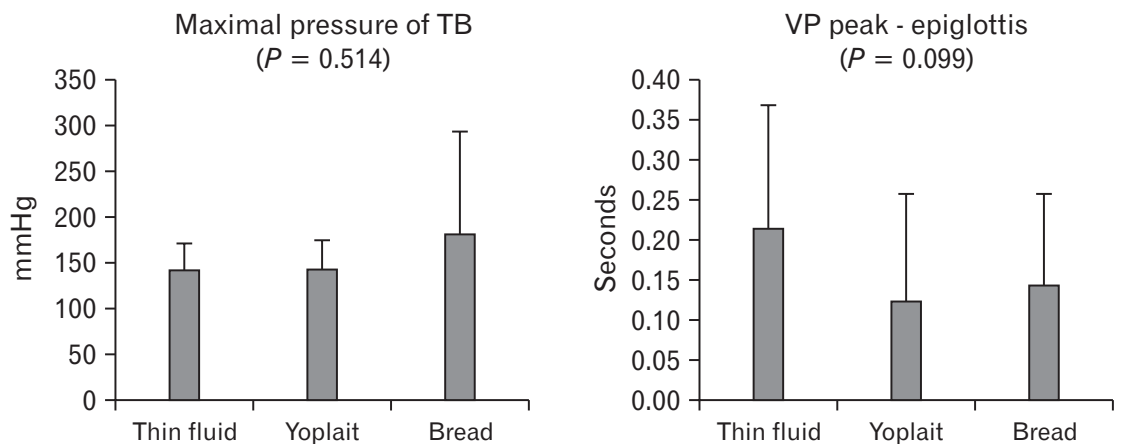

Figure 2. These figures show the comparisons according to volume and texture. (A) Histogram for "the comparison between groups according to volume". (B) Histogram for "the comparison between groups according to texture". VP, velopharynx; UES, upper esophageal sphincter; TB, tongue base. 
Table 3. The Visuospatial Variables of High-resolution Manometry According to Texture

\begin{tabular}{|c|c|c|c|c|c|c|}
\hline & & \multirow{2}{*}{$\begin{array}{l}\text { Thin fluid } \\
(5 \mathrm{~mL})\end{array}$} & \multirow{2}{*}{$\begin{array}{c}\text { Yogurt } \\
(5 \mathrm{~mL})\end{array}$} & \multirow{2}{*}{$\begin{array}{c}\text { Bread } \\
(5 \mathrm{~mL})\end{array}$} & \multicolumn{2}{|c|}{ Correlation } \\
\hline & & & & & $r$ & $P$-value \\
\hline \multirow[t]{4}{*}{ VP } & Max pressure $(\mathrm{mmHg})$ & $232.45 \pm 107.66$ & $221.92 \pm 88.07$ & $210.49 \pm 80.26$ & -0.054 & 0.681 \\
\hline & Area $(\mathrm{mmHg} \cdot \mathrm{sec})$ & $49.60 \pm 32.80$ & $48.10 \pm 32.22$ & $54.90 \pm 39.47$ & 0.054 & 0.684 \\
\hline & Rise time (sec) & $0.16 \pm 0.08$ & $0.14 \pm 0.06$ & $0.17 \pm 0.14$ & -0.082 & 0.535 \\
\hline & Duration (sec) & $0.37 \pm 0.17$ & $0.35 \pm 0.15$ & $0.36 \pm 0.21$ & -0.068 & 0.607 \\
\hline \multirow[t]{4}{*}{ TB } & Max pressure $(\mathrm{mmHg})^{\mathrm{a}}$ & $142.14 \pm 30.31$ & $143.55 \pm 29.68$ & $181.20 .14 \pm 112.35$ & 0.085 & 0.514 \\
\hline & Area $(\mathrm{mmHg} \cdot \mathrm{sec})$ & $53.00 \pm 16.82$ & $48.80 \pm 10.83$ & $58.96 \pm 24.70$ & 0.116 & 0.373 \\
\hline & Rise time (sec) & $0.26 \pm 0.09$ & $0.29 \pm 0.09$ & $0.24 \pm 0.09$ & -0.095 & 0.465 \\
\hline & Duration (sec) & $0.57 \pm 0.16$ & $0.59 \pm 0.11$ & $0.58 \pm 0.12$ & 0.008 & 0.952 \\
\hline Low pharynx & Max pressure $(\mathrm{mmHg})$ & $486.58 \pm 150.17$ & $458.28 \pm 169.05$ & $451.47 \pm 148.94$ & -0.130 & 0.317 \\
\hline \multirow[t]{5}{*}{ UES } & Pre-UES max pressure $(\mathrm{mmHg})$ & $240.58 \pm 119.60$ & $209.31 \pm 67.50$ & $230.07 \pm 83.38$ & 0.027 & 0.838 \\
\hline & Post-UES max pressure $(\mathrm{mmHg})$ & $452.13 \pm 126.20$ & $386.39 \pm 110.71$ & $387.72 \pm 130.76$ & -0.223 & 0.084 \\
\hline & Min pressure $(\mathrm{mmHg})$ & $-6.21 \pm 5.43$ & $-5.97 \pm 9.51$ & $-11.50 \pm 12.14$ & -0.224 & 0.083 \\
\hline & Activity time (sec) & $0.69 \pm 0.13$ & $0.70 \pm 0.14$ & $0.70 \pm 0.25$ & -0.057 & 0.663 \\
\hline & Nadir duration (sec) & $0.38 \pm 0.10$ & $0.38 \pm 0.11$ & $0.33 \pm 0.12$ & -0.146 & 0.262 \\
\hline
\end{tabular}

${ }^{\mathrm{a}} \mathrm{P}<0.05$.

VP, velopharynx; TB, tongue base; UES, upper esophageal sphincter; Max, maximal; Min, minimal.

Table 4. The Time Variables of High-resolution Manometry According to Texture

\begin{tabular}{|c|c|c|c|c|c|c|}
\hline & & \multirow{2}{*}{$\begin{array}{l}\text { Thin fluid } \\
(5 \mathrm{~mL})\end{array}$} & \multirow{2}{*}{$\begin{array}{l}\text { Yogurt } \\
(5 \mathrm{~mL})\end{array}$} & \multirow{2}{*}{$\begin{array}{c}\text { Bread } \\
(5 \mathrm{~mL})\end{array}$} & \multicolumn{2}{|c|}{ Correlation } \\
\hline & & & & & $r$ & $P$-value \\
\hline \multirow[t]{6}{*}{ Time intervals } & VP onset - epiglottis (sec) & $0.36 \pm 0.19$ & $0.27 \pm 0.14$ & $0.32 \pm 0.19$ & -0.120 & 0.370 \\
\hline & VP onset - onset TB (sec) & $0.14 \pm 0.07$ & $0.16 \pm 0.10$ & $0.22 \pm 0.19$ & 0.205 & 0.117 \\
\hline & VP peak - epiglottis (sec) ${ }^{a}$ & $0.21 \pm 0.15$ & $0.12 \pm 0.13$ & $0.14 \pm 0.11$ & -0.219 & 0.099 \\
\hline & VP peak - TB peak (sec) & $0.31 \pm 0.10$ & $0.30 \pm 0.11$ & $0.26 \pm 0.11$ & -0.170 & 0.195 \\
\hline & VP onset - pre-UES (sec) & $0.26 \pm 0.27$ & $0.15 \pm 0.09$ & $0.21 \pm 0.18$ & -0.110 & 0.401 \\
\hline & VP onset - post-UES (sec) & $0.92 \pm 0.11$ & $0.90 \pm 0.13$ & $0.99 \pm 0.30$ & 0.019 & 0.884 \\
\hline \multirow[t]{3}{*}{ ROP } & ROP, VP (mmHg/sec) & $1810.9 \pm 1173.1$ & $1760.0 \pm 895.9$ & $1561.7 \pm 1002.5$ & -0.080 & 0.543 \\
\hline & $\mathrm{ROP}, \mathrm{TB}(\mathrm{mmHg} / \mathrm{sec})$ & $656.4 \pm 328.2$ & $559.2 \pm 217.1$ & $842.9 \pm 576.0$ & 0.122 & 0.350 \\
\hline & ROP, VP onset - post-UES (cm/sec) & $7.68 \pm 1.38$ & $8.00 \pm 1.57$ & $7.64 \pm 1.85$ & 0.014 & 0.918 \\
\hline
\end{tabular}

${ }^{\mathrm{a} P}<0.05$.

VP, velopharynx; TB, tongue base; UES, upper esophageal sphincter; ROP, rate of pressure generation.

contraction of the TB in HRM. The contraction of the VP and TB were faster than laryngeal elevation and pharyngeal constriction. The durations of UES relaxation was much shorter in the kinematic analysis than HRM (Fig. 3).

\section{Discussion}

The present study showed somewhat different results compared to a previous study. In the previous study using HRM for bolus volume, statistically significant differences were observed for total swallow duration, UES opening time, and minimal UES pressure.
Additional variables such as maximal VP pressure, duration of VP, and maximal TB pressure showed a correlation with bolus volume and approached, but did not reach significance at the 0.05 level. ${ }^{15}$

However, in the present study, the duration of VP and the area integral of VP (not the maximal pressure) were significantly different $(P<0.05)$. In the previous study, the maximal pressure of VP did not correlate with the volume and the area integral was not evaluated as a variable. ${ }^{15}$ Our result showed that the area integral of VP significantly correlated to the changes of volume. While maximal pressure can inform the important physiology of swallowing, it does not provide the complete aspect of the pharyngeal pressure 


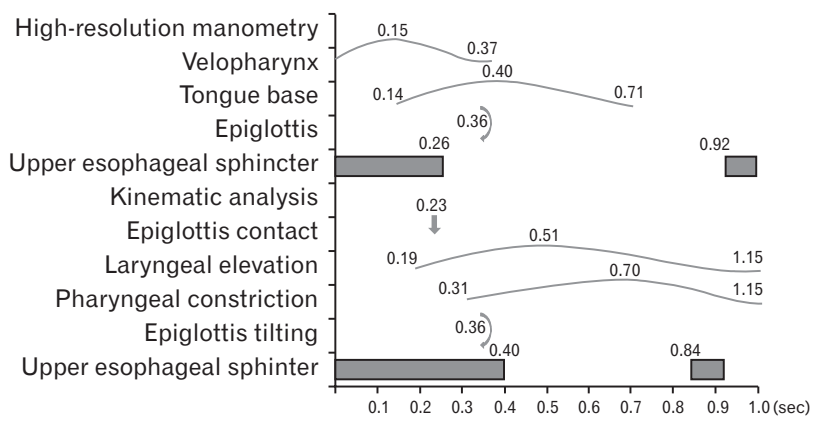

Figure 3. We synchronized the kinematic analysis and high-resolution manometry (HRM) studies based on epiglottis tilting. The contraction of the velopharynx and tongue base was faster than laryngeal elevation and pharyngeal constriction. The results of the HRM were more sensitive than those of the kinematic analysis.

generation. Measuring the area integrals offers more comprehensive information, because the area integrals represent the total pressure generated within a region of interest. When the information is combined with temporal data, the shape of the pressure curve is more revealed, and thus leads to better estimation of the pressures affecting bolus propulsion. ${ }^{17}$

There has been controversy regarding the change in TB pressure. Previous studies did not observe a change in TB pressure, ${ }^{1,4}$ but a recent study using HRM showed that the TB pressure had an inverse relationship with bolus volume. ${ }^{15}$ However, the correlation of the TB did not reach the significance level for maximal pressure $(P=0.199)$ and duration $(P=0.396)$, and only the ANCOVA analysis revealed significance. ${ }^{15}$ Our results showed that all parameters of the TB were not significant, and follow up study is required.

In the present study, we also verified the significant correlation of pre-UES maximal pressure, minimal pressure, activity time, and nadir UES duration. Among the significant parameters, pre-UES maximal pressure and nadir UES duration were verified for the first time in the present study.

Though some of our results were consistent, some were not compared with a previous HRM study. ${ }^{15}$ The UES opening time was significant in our and previous studies. The minimal pressure which showed marginal significance $(P=0.0566)$ in the previous study, ${ }^{15}$ was significant in our study $(P=0.003)$. The low pharyngeal pressure and post-UES maximal pressure were not significant in both the previous and our studies. ${ }^{15}$ The pre-UES maximal pressure which was not significant $(P=0.996)$ previously, ${ }^{15}$ was significant in our study $(P=0.012)$. We also verified that the nadir UES duration as a significant parameter.
There might be several causes for these results. The first might be the selection of the channel. The investigators of this study had difficulty in channel selections. The values of the selected channels are much different at 1 channel distance. Thus 4 investigators came together and selected the channels for VP, TB, and UES in the present study. The locations of the selected channels were usually maintained throughout the whole process. Therefore, we were able to reduce bias of channel selection. The second reason might be the location of the probe. If the sensors are continuous we could evaluate more accurately and precisely. As the sensors were located at 1 $\mathrm{cm}$ distance, the distance could have significant influence on the results.

In the present study, minimal UES pressure significantly correlated with bolus volume. The mean value from the raw data was $-11.65 \mathrm{mmHg}$ for dry swallow and $-2.95 \mathrm{mmHg}$ for drinking, but these values were much lower than the previous study which reports $-4 \mathrm{mmHg}$ for $1 \mathrm{~mL}$ swallow and $0 \mathrm{mmHg}$ for $20 \mathrm{~mL}$ drinking. ${ }^{15}$ As we used different equipment, the sensitivity of the equipment could affect the absolute value. Therefore, a comparison between the equipment is required.

The negative UES pressure is thought to be generated in part by laryngeal elevation and serves to move a bolus into the esophagus. In my opinion, we should consider the pressure effect of bolus itself. Previous studies did not consider that. As the volume of the bolus reaching the UES increases, the pressure generated by the bolus itself should increase while laryngeal elevation should be more restricted, leading to less negative pressure generation. Thus, we can postulate that $-11.65 \mathrm{mmHg}$ recorded for dry swallow is the intrinsic mean minimal pressure of the UES while the bolus volume leads to increased measurements.

Till now, there were no studies evaluating the effect of texture on pharyngeal phase and pressure. Our HRM study found out that all parameters were not significantly correlated to texture (Tables 3 and 4).

In previous studies using HRM, several parameters of pharyngeal phase were employed, ${ }^{7,15,17}$ but we used some new parameters. At the channels sensing TB peak pressure, we noticed a prominent high peak with short duration, sometimes summating with the TB peak pressure. When we compared HRM data with VFSS, we found out that these peaks represent the tilting of epiglottis. The tilting of the epiglottis is an important event in pharyngeal swallowing and may present significant information. Therefore, we used this peak as a timing variable.

We selected the epiglottis peak to measure the time intervals between the variables. As this peak could interfere with the maximal 
pressure and the area integral of TB, we used channels 1 level above or below the peak (the channel with the higher value was selected) for TB pressure measurement. However, some individuals did not show the epiglottic peak, probably due to the location of catheter. So this parameter for epiglottic tilting could not be applied to all patients. Therefore, if it is necessary to evaluate this parameter, we should adjust the manometric catheter thoroughly. As we employed the epiglottis tilting as a new parameter, we found significant difference between the VP peak and epiglottis (Table 4).

UES abnormalities seem to be the most common feature associated with dysphagia. This means that the UES requires fairly complex and appropriately timed sphincteric action. Bolus gravitational force may be sufficient to compensate for a dysfunctional $\mathrm{VP}$ or $\mathrm{TB}$, and the elevated VP pressure may adjust for low TB pressure. However, UES opening to facilitate the bolus passage to the esophagus and subsequent closing to prevent regurgitation and reflux are critical aspects of a functional swallow. ${ }^{17}$ Therefore, UES analysis is important for HRM analysis.

We can observe narrow peaks which move down to the UES and the formation of the last broad peak (Fig. 1). UES is composed of the inferior pharyngeal constrictor and cricopharyngeus. ${ }^{21}$ The inferior pharyngeal constrictor muscle is composed of mainly faster fiber (39\% type $1,61 \%$ type 2 ). ${ }^{22}$ On the other hand, the cricopharyngeus muscle is $25-35 \mu \mathrm{m}$ in diameter and is a small striated muscle. The fiber type is mainly highly oxidative, slow twitch type 1 fiber and a small portion of fast twitch type 2 (70\% type I, 30\% type II $)^{22,23}$ Therefore these narrow peaks should represent the pharyngeal peristalsis from the inferior pharyngeal constrictor muscle (mainly fast twitch fiber, type 2), and the broad peak should represent UES peak from the cricopharyngeus muscle (mainly slow twitch fiber, type 1). To distinguish the shallow and broad peaks, we selected the channel that showed the maximal peak for narrow peaks and named it "low pharyngeal pressure," while we measured the broad peak and named it "UES peak." This study is the first study that distinguishes the inferior pharyngeal constrictor muscle from the cricopharyngeus muscle by HRM.

In the present study, we analyzed the chronological sequence of normal swallowing and compared the parameters between VFSS and HRM (Fig. 1). The contraction of the VP and TB were faster than laryngeal elevation and pharyngeal constriction. In addition, the onset of UES opening measured by HRM was faster than the onset of UES opening in the kinematic study. In other words, the results of HRM were more sensitive than those of the kinematic analysis. The parameters of HRM are based on precise anatomic structure while the kinematic analysis reflects the actions of multiple anatomic structures. HRM appears to be applicable to accurate research for patients with dysphagia.

In previous studies using EMG, the pre-UES peak corresponded to the foreburst activity which is regarded as a protective reflex. The post-UES peak corresponds to the rebound burst activity. The foreburst activity is found in $69 \%$ of the normal population and the rebound burst activity is found in $100 \%$ of the normal population, and is clearly distinguished by the pharyngeal peristaltic wave. ${ }^{21,24}$ In a previous study using HRM, maximum pre-opening UES pressures were shown to be sensitive and accurate indicators of dysphagia, demonstrating the impact of the UES dysfunction in swallowing physiology. ${ }^{17}$ This information could be important for further understanding of HRM parameters.

Our present study has some limitations. First, we evaluated only 10 healthy subjects and did not evaluate patients with dysphagia. Further studies to evaluate the effect of volume and texture in dysphagic patients are required. Second, the absolute values of the present study were much different from those of previous studies which used a different system and catheter (ManoScan, Los Angeles, CA, USA). ${ }^{16}$ The reasons might be due to the different diameter of catheters and analyzing protocol. Therefore, absolute values should be used in the same evaluation system. The linear correlation analysis for volume showed significant correlation for area integral of VP, duration of VP, pre-UES maximal pressure, minimal UES pressure, UES activity time, and nadir UES duration. On comparison among the 5 groups, post-UES maximal pressure, minimal UES pressure, nadir UES duration, and the time interval between the VP onset and TB onset were significantly different. In the correlation with texture, the maximal pressure of $\mathrm{TB}$ and the interval from VP peak and epiglottis was significantly correlated. Other parameters were not significantly different. In comparison among the 3 groups, the interval between VP peak and epiglottis was significantly different.

The parameters of HRM were more sensitive than those of the kinematic analysis. Therefore the parameters of both equipments should be used according to their purposes of researches.

Financial support: This research was supported by Basic Science Research Program through the National Research Foundation of Korea (NRF) funded by the Ministry of Science, ICT, and Future Planning (NRF-2013R1A1A1004622).

\section{Conflicts of interest: None.}

Author contributions: Ju Seok Ryu prepared manuscript and 
set up high-resolution manometry; and Donghwi Park, Yoongul Oh, Seok Tae Lee, and Jin Young Kang assisted data collection and analysis.

\section{References}

1. Perlman AL, Schultz JG, VanDaele DJ. Effects of age, gender, bolus volume, and bolus viscosity on oropharyngeal pressure during swallowing. J Appl Physiol 1985 1993;75:33-37.

2. Butler SG, Stuart A, Castell D, Russell GB, Koch K, Kemp S. Effects of age, gender, bolus condition, viscosity, and volume on pharyngeal and upper esophageal sphincter pressure and temporal measurements during swallowing. J Speech Lang Hear Res 2009;52:240-253.

3. Dantas RO, Kern MK, Massey BT, et al. Effect of swallowed bolus variables on oral and pharyngeal phases of swallowing. Am J Physiol 1990;258(5 Pt 1):G675-G681.

4. Pouderoux P, Kahrilas PJ. Deglutitive tongue force modulation by volition, volume, and viscosity in humans. Gastroenterology 1995;108:14181426.

5. Kahrilas PJ, Logemann JA, Lin S, Ergun GA. Pharyngeal clearance during swallowing: a combined manometric and videofluoroscopic study. Gastroenterology 1992;103:128-136.

6. Mielens JD, Hoffman MR, Ciucci MR, Jiang JJ, McCulloch TM. Automated analysis of pharyngeal pressure data obtained with highresolution manometry. Dysphagia 2011;26:3-12.

7. McCulloch TM, Hoffman MR, Ciucci MR. High-resolution manometry of pharyngeal swallow pressure events associated with head turn and chin tuck. Ann Otol Rhinol Laryngol 2010;119:369-376.

8. Takasaki K, Umeki H, Kumagami H, Takahashi H. Influence of head rotation on upper esophageal sphincter pressure evaluated by high-resolution manometry system. Otolaryngol Head Neck Surg 2010;142:214217.

9. Geng Z, Hoffman MR, Jones CA, McCulloch TM, Jiang JJ. Threedimensional analysis of pharyngeal high-resolution manometry data. Laryngoscope 2013;123:1746-1753.

10. Hoffman MR, Mielens JD, Ciucci MR, Jones CA, Jiang JJ, McCulloch TM. High-resolution manometry of pharyngeal swallow pressure events associated with effortful swallow and the Mendelsohn maneuver. Dysphagia 2012;27:418-426.
11. Ryu JS, Park DH, Kang JY. Application and interpretation of highresolution manometry for pharyngeal dysphagia. J Neurogastroenterol Motil 2015;21:283-287.

12. Leonard R, Kendall K. Dysphagia assessment and treatment planning. San Diego: Plural Publishing Group, Inc. 2008:12-17.

13. Ghosh SK, Pandolfino JE, Zhang Q, Jarosz A, Kahrilas PJ. Deglutitive upper esophageal sphincter relaxation: a study of 75 volunteer subjects using solid-state high-resolution manometry. Am J Physiol Gastrointest Liver Physiol 2006;291:G525-G531.

14. Fox MR, Bredenoord AJ. Oesophageal high-resolution manometry: moving from research into clinical practice. Gut 2008;57:405-423.

15. Hoffman MR, Ciucci MR, Mielens JD, Jiang JJ, McCulloch TM. Pharyngeal swallow adaptations to bolus volume measured with highresolution manometry. Laryngoscope 2010;120:2367-2373.

16. Lin T, Xu G, Dou Z, Lan Y, Yu F, Jiang L. Effect of bolus volume on pharyngeal swallowing assessed by high-resolution manometry. Physiol Behav 2014;128:46-51.

17. Mielens JD, Hoffman MR, Ciucci MR, McCulloch TM, Jiang JJ. Application of classification models to pharyngeal high-resolution manometry. J Speech Lang Hear Res 2012;55:892-902.

18. Choi KH, Ryu JS, Kim MY, Kang JY, Yoo SD. Kinematic analysis of dysphagia: significant parameters of aspiration related to bolus viscosity. Dysphagia 2011;26:392-398.

19. Lee SI, Yoo JY, Kim M, Ryu JS. Changes of timing variables in swallowing of boluses with different viscosities in patients with dysphagia. Arch Phys Med Rehabil 2013;94:120-126.

20. Kendall KA, McKenzie S, Leonard RJ, Goncalves MI, Walker A. Timing of events in normal swallowing: a videofluoroscopic study. Dysphagia 2000;15:74-83.

21. Singh S, Hamdy S. The upper oesophageal sphincter. Neurogastroenterol Motil 2005;17(suppl 1):3-12.

22. Mu L, Sanders I. Neuromuscular compartments and fiber-type regionalization in the human inferior pharyngeal constrictor muscle. Anat Rec 2001;264:367-377.

23. Bonington A, Mahon M, Whitmore I. A histological and histochemical study of the cricopharyngeus muscle in man. J Anat 1988;156:27-37.

24. Ertekin C, Aydogdu I. Electromyography of human cricopharyngeal muscle of the upper esophageal sphincter. Muscle Nerve 2002;26:729739 . 